\title{
MYXOID LIPOSARCOMA OF THE SPERMATIC CORD MIMICKING LEFT INGUINAL HERNIA: A RARE CASE REPORT
}

\author{
Sanjay Nigam ${ }^{1}$, Shalini Shukla², Neha Ahuja ${ }^{3}$, Jayant Rai ${ }^{4}$, Parul Joshi ${ }^{5}$ \\ 1 Professor, Department of Pathology, Rama Medical College and Research Centre, Kanpur. \\ ${ }^{2}$ Lecturer, Department of Pathology, GSVM Medical College, Kanpur. \\ ${ }^{3}$ Consultant Pathologist, Department of Pathology, Paliwal Diagnostics Private Limited. \\ ${ }^{4}$ Second Junior Resident, Department of Pharmacology, GMC, Surat. \\ ${ }^{5}$ Associate Professor, Department of Pathology, Rama Medical College and Research Centre, Kanpur.
}

\section{ABSTRACT}

Myxoid liposarcoma of the spermatic cord is a rare condition. Preoperative diagnosis is difficult since the clinical findings are very similar to that of inguinal hernia. We report a rare case of myxoid liposarcoma of spermatic cord in a 55-year-old male, who was clinically diagnosed with left inguinal hernia. Surgical excision specimen showed globular lump, which measures $13 \times 12 \times 6 \mathrm{~cm}$ and cut surface show myxoid gelatinous areas. Microscopic examination showed features of myxoid liposarcoma.

\section{KEYWORDS}

Myxoid, Liposarcoma, Spermatic Cord, Hernia.

HOW TO CITE THIS ARTICLE: Sanjay Nigam, Shalini Shukla, Neha Ahuja, Jayant Rai, Parul Joshi. "Myxoid Liposarcoma of the Spermatic Cord Mimicking Left Inguinal Hernia: A Rare Case Report." Journal of Evolution of Medical and Dental Sciences 2015; Vol. 4, Issue 96, November 30; Page: 16198-16200, DOI: 10.14260/jemds/2015/2380

\section{INTRODUCTION}

Liposarcoma are malignant tumours derived embroyologically from mesodermal tissue. It is the most common soft tissue sarcoma in adults.[1] It can occur in any part of the body that contain fatty tissue. The two major sites of liposarcoma are the extremities, especially the thigh and the retroperitoneum which account for about two-thirds of all cases. ${ }^{[2]}$ Its clinical presentation characterized by symptom, which is usually late and nonspecific.[3] They presumably have a good prognosis. Well differentiated liposarcoma have no metastasis with high five year survival rates.[4] Since the inguinal region communicates with the retroperitoneum, liposarcoma in both the regions may be detected during hernia repair operations. ${ }^{[5]}$ We report a rare case of liposarcoma of spermatic cord, which clinically presented as indirect inguinal hernia.

\section{CASE REPORT}

A 55-year-old male presented with swelling and pain in the scrotal and left inguinal region since 2 years with sudden increase in the pain for last one month. He was a known hypertensive and on treatment. Local examination showed swelling in the left scrotal region measuring $13 \times 13 \mathrm{cms}$. The mass was larger with increased abdominal pressure when the patient was standing, but smaller when he was supine. It was tender and soft in consistency. Trans-illumination testing was negative.

There were no constitutional symptoms, voiding complaints, history of local trauma, infection, loss of appetite, weight loss or hereditary disease. All pre-operative laborative investigations including complete blood count, biochemistry and serological investigations and chest $x$-ray were within normal limits. Scrotal ultrasonography showed bilateral hydrocele with left inguinoscrotal hernia.

Financial or Other, Competing Interest: None.

Submission 26-10-2015, Peer Review 27-10-2015,

Acceptance 20-11-2015, Published 30-11-2015.

Corresponding Author:

Dr. Sanjay Nigam,

Professor

Department of Pathology,

Rama Medical College and Research Centre, Kanpur.

E-mail: sknigam@yahoo.com

DOI:10.14260/jemds $/ 2015 / 2380$
The clinical diagnosis of bilateral hydrocele with left inguinal hernia was made and treated surgically for hydrocele and hernia. At operation, single grayish white swelling was seen along the spermatic cord, which were excised and sent for histopathological examination. Gross examination showed single globular grayish white lipomatous mass measuring $13 \times 12 \times 6 \mathrm{cms}$. Cut section of the lipomatous mass was grayish white to yellow with myxoid gelatinous areas. (Figure 1,2) Microscopic examination showed a tumour composed of proliferating lipoblasts in different stages of maturation. (Figure 3,4) Background show myxoid appearance and show prominent anastomosing thin walled capillary network. (Figure 5, 6) Final diagnosis of myxoid liposacroma was made.

\section{DISCUSSION}

Liposarcoma of paratesticular tissues (Spermatic cord, testicular tunics or epididymis), which was first reported in 1952 is a rare neoplasm that comprises approximately $5 \%$ to $7 \%$ of paratesticular sarcomas. Most of them originate in the spermatic cord. $[6]$ but some originate in the retroperitoneum and develop in the inguinal region and involve the spermatic cord. [7]

The typical clinical presentation of LSC has been usually a slowly growing, non-tender, painless, nodular mass of varying size, located intrascrotally above the testis or in the groin. Only a few cases presented with a painful node.[6,8,9] preoperative diagnosis was not common and was often confused with an inguinal hernia, hydrocele or spermatocele, or a tumor of the testis or epididymis. ${ }^{[7,8]}$ In the present case, the scrotal mass was palpable when the patient was in upright position and disappeared when he was lying down. It was thus easily mistaken for an inguinal hernia.

High-resolution ultrasonography, computed tomography with contrast and Magnetic Resonance Imaging (MRI) have become the imaging modalities of choice for the examination of the scrotum and its contents and all can provide useful information about the lipomatous nature of these masses. ${ }^{[8]}$ Ultrasonography typically reveals a solid, hyperechoic, heterogenous lesion separate from the testicle and similar to benign lipomas. CT usually demonstrates a mass with fat attenuation intermixed with non-lipomatous septa or soft tissue nodules.[10] 
Grossly, liposarcoma resembles lipoma, especially the lipoblastic types, but the surface may show foci with a mucinous appearance. In large tumors, multinodularity and multilocularity of fatty or cartilaginous tissue were often observed. ${ }^{[9]}$ Histologically, liposarcomas are divided into well differentiated, de-differentiated (High and low grade) and myxoid/round cell. Most LSC were low grade, welldifferentiated tumors. In the literature we reviewed WellDifferentiated Liposarcoma (WDL) and found Myxoid Liposarcoma (ML) to be the most commonly encountered type, accounting for $48.7 \% \quad(19 / 39)$ and $25.6 \%$ (10/39), respectively. Of 19 cases with WDL, 7 patients had a sclerosing subtype, 11 did not report a specific subtype, and only 1 presented with a mixture of WDL and PDL. Dedifferentiated Liposarcoma (DL) and (Pleomorphic Liposarcoma) PL were considered to be highly malignant, and had an incidence of $17.9 \%(7 / 39)$ and 5.1\% (2/39) respectively. Some uncommon histological findings have been reported. Domşa described a mixed type liposarcoma with well-differentiated major pleomorphic and minor sclerosing components.[11] Ikinger et al. reported a case of a Well-Differentiated Myxoid Liposarcoma (WDML) combined with angiolipoma. Although immunohistochemical markers were applied in several cases, accurate diagnoses depended on morphological criteria.

Liposarcomas tend to spread primarily by local extension. Once diagnosed or suspected preoperatively, radical orchiectomy with wide local excision and high ligation of the spermatic cord is recommended.[12] as was performed in our case. Retroperitoneal lymph node dissection is not indicated unless there is evidence of metastasis. The resection must be wide and scrotectomy may be considered in patients with high-grade tumors to prevent local recurrence.[13]

All liposarcoma types frequently recur and spread by direct invasion. Liposarcoma is relatively radiosensitive and radiotherapy is regarded as useful to prevent local recurrence. Radiotherapy is only recommended in selected patients whose pathological findings show intermediate or high histological grade or recurrent form. There is no consensus on the benefit of adjuvant chemotherapy. Given the high rate of local recurrence of LSC (55 to 70\%), long-term periodic follow-up is mandatory.

In spite of the likelihood of recurrence, the prognosis was satisfactory and the rate of mortality was reduced if radical orchiectomy resulted in complete clearance with a negative margin. Even if patients underwent incomplete resection, improved disease-free survival could be achieved by re-operative wide resection.[12] Tumor size and absence of metastasis at diagnosis remained significant predictors of disease-specific survival.[14]

\section{CONCLUSION}

We report a rare variety of spermatic cord mass having a misleading presentation. It should be highly suspected in patients complaining of recurrent hernias of the inguinal region. Therefore, awareness and histopathological confirmation of fatty masses in the inguinal region is necessary as liposarcoma have prolonged clinical course with late recurrences. All surgeons should be aware of this malignancy. The treatment of choice is radical orchidectomy and wide excision with high ligation of the spermatic cord. If the margin is in doubt, adjuvant radiotherapy is indicated.

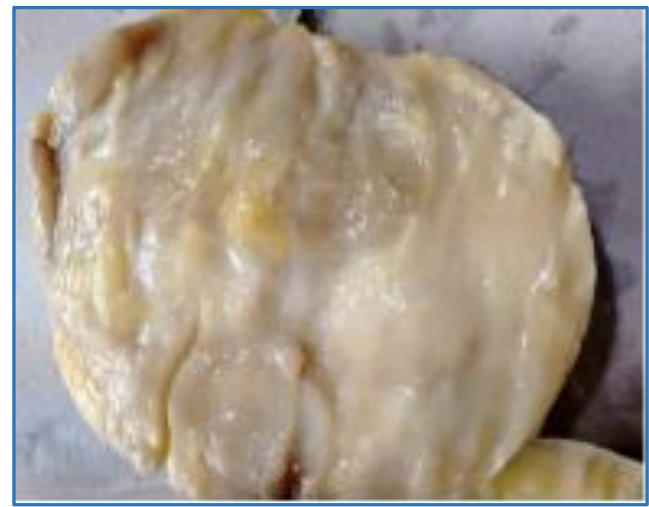

Fig. 1: Greyish White Lesion

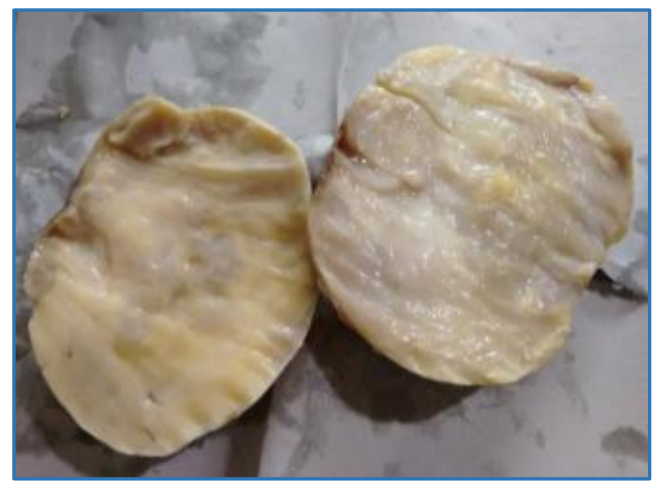

Fig. 2: Myxoid Gelatinous Areas

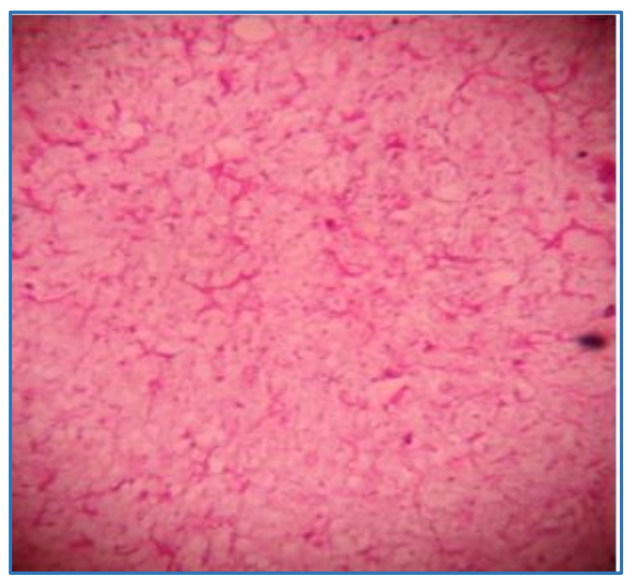

Fig. 3: 40X Chicken Wire Appearance

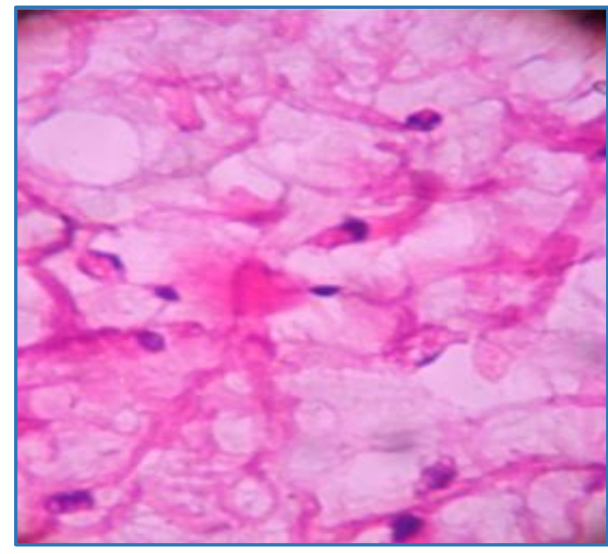

Fig. 4: 400X Presence of Lipoblasts. 


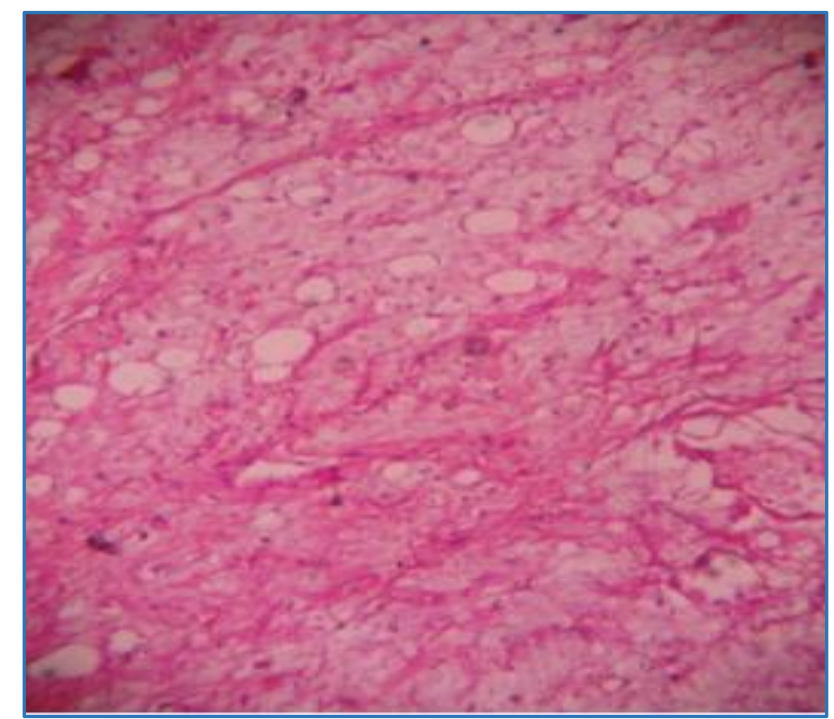

Fig. 5: 100X Proliferating Lipoblasts

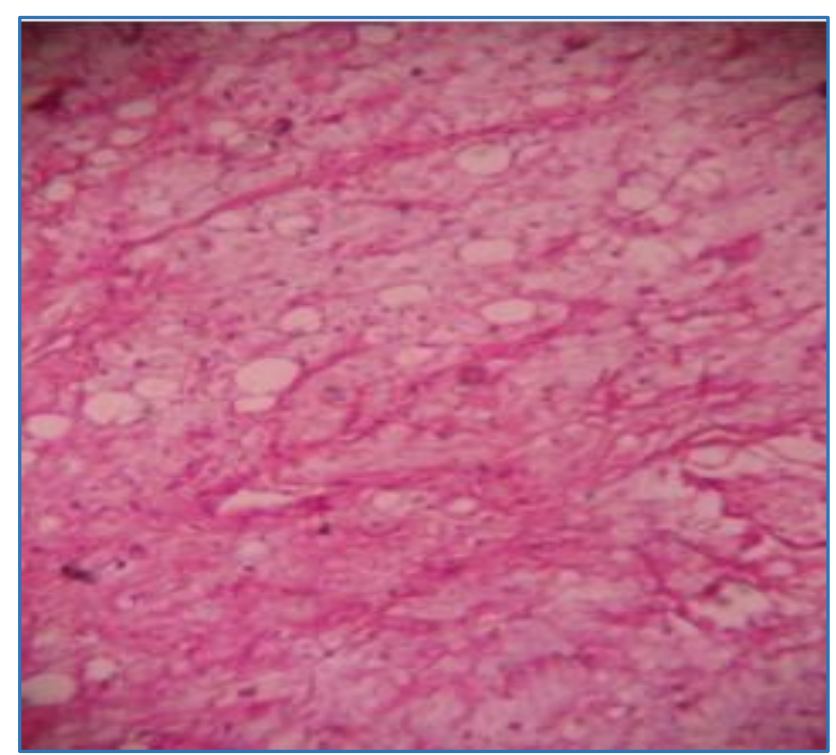

Fig. 6: Thin Walled Capillaries with Myxoid Areas

\section{REFERENCES}

1. Enterline HT, Culberson JD, Rochlin DB, Brady LW. Liposarcoma. A clinical and pathological study of 53 cases. Cancer 1960;13:932-950.

2. Channara Sookluan. Giant Retroperitoneal Liposarcoma Presenting as Indirect Inguinal Hernia. J Parpokklao Hosp Clin Med Educat Center 2006;22:151-7.

3. Hirofumi N, Yoshio N, Minoru H, Tomoki Y, Kaori S, Hirokazu U, et al. Retroperitoneal Liposarcoma Presenting a Indirect Inguinal Hernia. Acta Med. Okayama 2001;55:51-4.

4. Elizabeth Montgomery, Cyril Fisher. Paratesticular Liposarcoma-Clinicopathologic Study. American Journal of Surgical Pathology 2003;27:40-7.

5. Elizabeth Montgomery, Robert Buras. Incidental Liposarcomas identified during Hernia repair operations. Journal of Surgical Oncology 1999;71:503.

6. Treadwell T, Treadwell MA, Owen M, McConnell TH, Ashworth CT: Giant liposarcoma of the spermatic cord. South Med J 1981;74:753-755.

7. Noguchi H, Naomoto Y, Haisa M, Yamatsuji T, Shigemitsu K, Uetsuka H, Hamasaki S, Tanaka N: Retroperitoneal liposarcoma presenting an indirect inguinal hernia. Acta Med Okayama 2001;55:51-54.

8. Hassan JM, Quisling SV, Melvin WV, Sharp KW: Liposarcoma of the spermatic cord masquerading as an incarcerated inguinal hernia. AmSurg 2003;69:163165.

9. Hsu YF, Chou YY, Cheng YH: Spermatic cord myxoid liposarcoma presenting as an incarcerated inguinal hernia: report of a case and review of literatures. Hernia 2012;16:719-722.

10. Papageorgiou MS, Dadakas G, Donev K: Liposarcoma of the spermatic cord: a case report. Case Report Med 2011;2011:197-584.

11. Domşa I, Olinici CD, Crișan D. Spermatic cord mixed liposarcoma: case report and review of the literature. Rom J Morphol Embryol 2008;49:105-109.

12. Coleman J, Brennan MF, Alektiar K, Russo P: Adult spermatic cord sarcomas: management and results. Ann SurgOncol 2003;10:669-675.

13. Montgomery E, Buras R: Incidental liposarcomas identified during hernia repair operations. J SurgOncol 1999;71:50-53.

14. Dotan ZA, Tal R, Golijanin D, Snyder ME, Antonescu C, Brennan MF, Russo P: Adult genitourinary sarcoma: the 25-year Memorial Sloan-Kettering experience. J Urol 2006;176:2033-2038. 